\title{
ALVAC(2) Melanoma Multi-antigen Vaccine
}

National Cancer Institute

\section{Source}

National Cancer Institute. ALVAC(2) Melanoma Multi-antigen Vaccine. NCI Thesaurus. Code C73998.

A therapeutic cancer vaccine, based on a replication-defective recombinant canarypox virus (ALVAC) encoding multiple melanoma antigens, with potential immunostimulatory and antineoplastic activities. Vaccination with ALVAC(2) melanoma multi-antigen therapeutic vaccine may stimulate the host immune system to mount an immune response against antigen-expressing melanoma cells, resulting in inhibition of tumor growth and/or metastasis. 